\title{
FGF-2 is overexpressed in myoepithelial cells of carcinoma ex-pleomorphic adenoma in situ structures
}

\author{
ELIZABETH F. MARTINEZ ${ }^{1 *}$, ANA P.D. DEMASI ${ }^{*}$, LUCYENE MIGUITA ${ }^{1}$, \\ ALBINA ALTEMANI $^{2}$, NEY S. ARAÚJO ${ }^{1}$ and VERA C. ARAÚJO ${ }^{1}$ \\ ${ }^{1}$ Department of Oral Pathology, São Leopoldo Mandic Institute and Research Center; \\ ${ }^{2}$ Department of Pathology, State University of Campinas, Campinas, SP, Brazil
}

Received January 12, 2010; Accepted March 3, 2010

DOI: 10.3892/or_00000840

\begin{abstract}
Increasing emphasis has been placed on the role of myoepithelial cells, the contractile components of secretory glands, in the in situ to invasive carcinoma transition. These cells are placed at the interface between luminal epithelial cells and the stromal compartment, which favors their crosstalk with all other cell types comprising the tumor microenvironment. To obtain some clues about this cross-talk and also to better understand our previous immunoprofile study of myoepithelial cells in salivary gland carcinoma ex-pleomorphic adenoma (CXPA), we investigated FGF-2 expression in CXPA in situ structures as well as in cells cultured under conditions attempting to simulate the cellular interactions of this tumor stage. We have observed by immunohistochemistry that myoepithelial cells of CXPA in situ structures overexpress FGF-2. In addition, our results supported by qPCR and Western blotting, demonstrated that the expression of FGF-2 in the benign myoepithelial cells was in fact increased by stimulation with the conditioned medium from malignant cells. Low molecular weight FGF-2, known to be primarily released from the cells to exert its biological activity through receptors, was the predominant FGF-2 form detected in the benign myoepithelial cells. Specific FGF-2 receptors were found in the malignant epithelial but not in the benign myoepithelial cells of CXPA, indicating a paracrine role for benign myoepithelial cell-derived FGF-2. Abnormal paracrine myoepithelial/epithelial cell interactions and also myoepithelial/ stromal cell interactions could favor tumor growth, invasion and metastasis.
\end{abstract}

Correspondence to: Dr Elizabeth F. Martinez, Departamento de Patologia Oral, Faculdade de Odontologia e Centro de Pesquisas São Leopoldo Mandic, Rua José Rocha Junqueira 13, CEP 13045-610, Campinas, SP, Brazil

E-mail: efmartinez@usp.br

*Contributed equally

Key words: carcinoma ex-pleomorphic adenoma, in situ carcinoma, FGF-2, FGF-2 receptors, myoepithelial cells

\section{Introduction}

Carcinoma ex-pleomorphic adenoma (CXPA) is a rare salivary gland malignancy, usually derived from a longstanding or a recurrent benign tumor, the pleomorphic adenoma (PA) (1). In most cases (75\%), epithelial cells suffer transformation (2). Initially, carcinoma cells replace neoplastic luminal cells whilst bordered by an intact layer of benign myoepithelial cells of the pre-existing pleomorphic adenoma, characterizing the in situ structures. Next, the carcinoma cells break this myoepithelial border and invade into the surrounding stroma (2). Studying in situ structures of CXPA, we observed that the benign myoepithelial cells presented higher levels of myoepithelial cell markers (CK14, $\alpha$-smooth muscle actin, calponin, P63, CD10 and D2-40), laminin and maspin, than their counterparts in benign areas of pleomorphic adenoma (PA) (3) suggesting that benign myoepithelial cells could achieve full differentiation when in contact with malignant epithelial cells. It was demonstrated with mammary gland cells that differentiation towards the myoepithelial phenotype is associated with increased production of basic fibroblast growth factor (bFGF, also known as FGF-2), implying that this growth factor could play a major role in gland development (4).

Myoepithelial cells are the contractile components of the ductal and acini network of secretory glands, disclosing features indicative of a dual epithelial-like and muscle-like differentiation. In conjunction with the basement membrane, myoepithelial cells are placed at the interface between luminal epithelial cells and the stromal compartment. Thanks to this strategic location, increasing emphasis has been placed on the role of myoepithelial cells in the in situ to carcinoma transition (5-8). These cells provide a physical barrier that hold abnormally proliferating luminal cells within the duct. It has been hypothesized that cell death-mediated disruption of this barrier constitutes a prerequisite for tumor invasion and metastasis (9). Besides a physical restriction, myoepithelial cells also release paracrine factors which may influence bilaterally nearby cell populations. On one side, myoepithelial cells may exert antiproliferative effects, induce apoptosis and modulate polarity of neoplastic epithelial cells $(10,11)$. On the other side, they mold the stromal environment via deposition of an abundant extracellular matrix frequently devoid of blood vessels and stromal cells (6). 
Table I. Gender, age, localization, component and degree of invasion of CXPA.

\begin{tabular}{clclll}
\hline Case & Gender & Age (years) & Salivary gland & Component & Degree of invasion \\
\hline 1 & Male & 58 & Parotid & Epitehlial & Intracapsular \\
2 & Female & 37 & Submandibular & Epithelial & Intracapsular \\
3 & Female & 65 & Parotid & Epithelial & Minimally invasive \\
4 & Male & 74 & Parotid & Epithelial & Minimally invasive \\
5 & Female & 45 & Parotid & Epithelial & Minimally invasive \\
6 & Female & 59 & Parotid & Epithelial & Minimally invasive \\
7 & Male & 38 & Parotid & Epithelial & Intracapsular \\
8 & Female & 52 & Parotid & Epithelial & Intracapsular \\
\hline
\end{tabular}

Table II. Primary polyclonal antibodies.

\begin{tabular}{lccc}
\hline Antibody & Immunohistochemical dilution & Immunofluorescence dilution & Host \\
\hline FGF-2 & $1: 100$ & $1: 50$ & Rabbit \\
FGFR-1 (Flg) & $1: 150$ & $1: 100$ & Rabbit \\
FGFR-2 $($ Bek) & $1: 50$ & $1: 50$ & Rabbit \\
\hline
\end{tabular}

a Santa Cruz Biotechnogy, Inc., CA, USA.

FGF-2 exists in five isoforms, generated by alternative translation initiation of a single mRNA. The $18 \mathrm{kDa}$, also known as low molecular weight (LMW) form, is primarily localized in the cytosol and is efficiently secreted. The others, collectively referred to as high molecular weight (HMW) FGF-2, are found predominantly in the nucleus, targeted to this cellular compartment by a nuclear localization sequencelike signal (12-14). The $18 \mathrm{kDa}$ FGF-2 acts via four FGF specific tyrosine kinase receptors (FGFR1-FGFR4), in concert with soluble or cell surface-bound heparin and heparanproteoglycans, to promote activation of the subsequent intracellular signaling cascade and induction of the biological responses $(12,15,16)$. In contrast, HMW FGF-2 acts in a receptor-independent manner, directly regulating gene expression $(13,14)$. Whatever the manner of action, FGF-2 has been implicated in a variety of biological processes that entail cell growth, differentiation, migration, chemotaxis and angiogenesis $(12,14,17,18)$.

In this study, we investigated FGF-2 expression in the in situ areas of CXPA and also employed an in vitro study as an attempt to mimic the environmental context in which the cross-talk between malignant epithelial cells and adjacent myoepithelial cells may guide disease outcome, progression or regression.

\section{Materials and methods}

Immunohistochemistry. The present study protocol was approved by the Ethics Committee of São Leopoldo Mandic Institute and Dental Research Center, Campinas, Brazil (Protocol no. 07/124).
From 20 cases of CXAP retrieved from the files of the Department of Clinical Pathology at the State University of Campinas Medical School, Campinas, Brazil, 8 cases presenting in situ structures were selected, with epithelial (luminal) malignization (19), classified as intracapsular and minimally invasive carcinoma. The clinical data of selected cases are shown in Table I. Contrary to that occurring in in situ breast cancer, myoepithelial cells of CXPA in situ structures are not normal, they are neoplastic benign cells of PA.

Serial sections $(3 \mu \mathrm{m})$ were obtained from paraffinembedded samples, dewaxed and processed to antigen retrieval. Endogenous peroxidase was blocked by incubation with 3\% hydrogen peroxide and methanol (1:1). After washing, sections were incubated with primary polyclonal antibodies (Table II). Signal detection was performed using the Dako EnVision Peroxidase (Dako, Carpinteria, CA, USA), followed by a diaminobenzidine chromogen solution and counterstaining with Mayer's hematoxylin, executed by Dako Autostainer Plus (DakoCytomation, Carpinteria, CA, USA).

Normal salivary gland and benign PA areas of each specimen were taken as control. Omission of the primary antibody constituted the negative control. The sections were qualitatively evaluated by three examiners.

Cell culture. Benign myoepithelial cells were obtained from explants of PA tumors provided by surgery from three different donors. This study was conducted following the approval of the Ethics Committee of São Leopoldo Mandic Institute and Dental Research Center (Protocol no. 09/0014).

The cells were cultured in Dulbecco's modified Eagle medium $\left(\right.$ DMEM $\left.^{\circledR}\right)$ (Sigma, St. Louis, MO, USA) supple- 

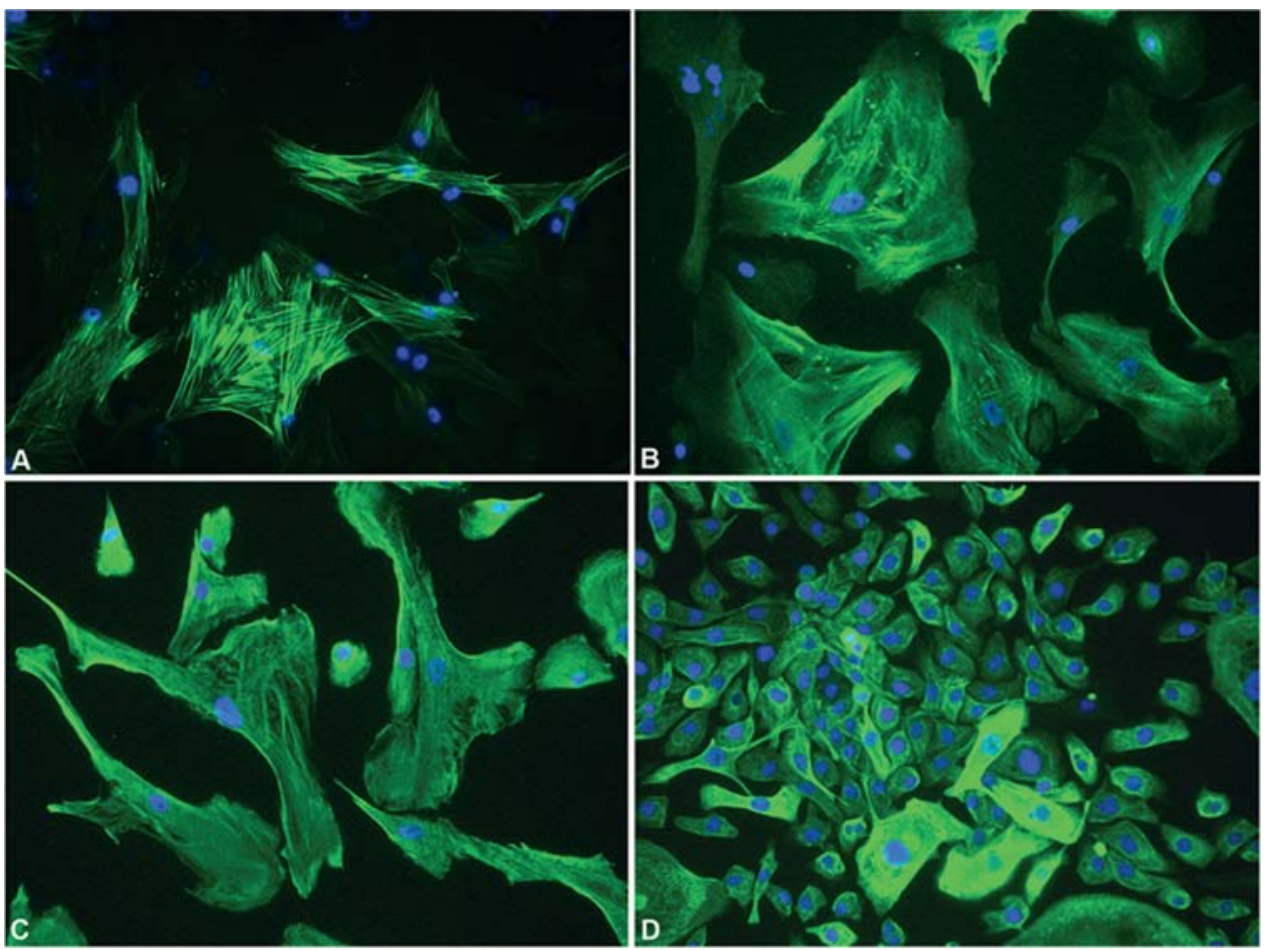

Figure 1. Characterization of myoepithelial cells from PA. Immunostaining for $\alpha$-AML (A), calponin (B) and vimentin (C) in benign myoepithelial cells from PA and AE1/AE3 in squamous cell carcinoma cells (HN30) (D). Most of the benign myoepithelial cells were positive for $\alpha$-AML (A) and calponin (B), and all immunoreactive for vimentin (C). All HN30 cells were positive for AE1/AE3 (D). Nuclei stained with DAPI appear in blue. Original magnification (A-D), x200.

mented with $1 \%$ antimycotic-antibiotic solution (10000 units of penicillin, $10 \mathrm{mg}$ of streptomycin and $25 \mu \mathrm{g}$ of amphotericin B per $\mathrm{ml}$ in $0.9 \%$ sodium chloride; Sigma $\left.{ }^{\circledR}\right)$, containing $10 \%$ of donor calf serum (DCS; Gibco ${ }^{\circledR}$, Buffalo, $\mathrm{NY}$ ), plated in 60-mm diameter plastic culture dishes and incubated under standard cell culture conditions $\left(37^{\circ} \mathrm{C}, 100 \%\right.$ humidity, $95 \%$ air and $5 \% \mathrm{CO}_{2}$ ). After reached the confluence, the cells were detached with $0.05 \%$ trypsin and subculture at a density of 20000 cells/well $\left(\sim 110\right.$ cells $\left./ \mathrm{mm}^{2}\right)$. Cells at subculture levels 3 or 4 were characterized using anti- $\alpha$-smooth actin, anti-calponin and anti-vimentin (Fig. 1A-C). These cells were cultured in DMEM for $24 \mathrm{~h}$ (treated samples) and for 4 days (control samples).

For the in vitro induction with conditioned medium, squamous cell carcinoma cells (HN30, American Type Culture Collection, VA, USA) were characterized using anti-AE1/ AE3 antibody (Fig. 1D). The HN30 cells medium was removed $48 \mathrm{~h}$ after plating and benign myoepithelial cells from PA were incubated with this conditioned medium for 4 days.

Immunofluorescence. Cells grown on coverslips were fixed in methanol for $6 \mathrm{~min}$ at $20^{\circ} \mathrm{C}$, rinsed in PBS followed by blocking with $1 \%$ bovine albumin in phosphate buffer saline (PBS) for $30 \mathrm{~min}$ at room temperature. The primary polyclonal antibodies are described in Table II. Control staining reaction was performed using PBS as non-immune IgGs at the same dilution used for the primary antibody. The secondary antibody used was biotinylated anti-rabbit IgG (Vector Laboratories, Inc., Burlingame, CA, USA). Fluoresceinstreptavidin conjugated antibodies $\left(\right.$ Vector $\left.^{\circledR}\right)$ were used for the second step. After washing, preparations were mounted using Vectashield ${ }^{\circledR}$ DAPI-associated (4'-6-diamidino-2phenylindole) (Vector) and observed on a Zeiss Axioskop 2 conventional fluorescence microscope (Carl Zeiss MicroImaging $\mathrm{GmbH}$, Germany).

Real-time or quantitative PCR. Total RNA, extracted from benign myoepithelial (PA) cells with Tri Reagent (Molecular Research Center, OH, USA), was submitted to reverse transcription using the Superscript III First Strand cDNA Syntheis kit (Invitrogen, Carlsbad, CA, USA), according to the manufacturer's instructions. The primer sets were as follows: 5'GTGCTAACCGTTACCTGGCTAT-3' and 5'- CCAATCGT TCAAAAAAGAAACAC-3' for FGF-2; 5'- AGGCCAACCG CGAGAAG-3' and 5'-ACAGCCTGGATAGCAACGTA CA-3' for ACTB (ß-actin), used as internal gene reference. Quantitative real-time PCR was performed using a 7300 Real-Time PCR System (Applied Biosystems, Foster City, CA, USA) with SYBR Green as detection dye. Cycling conditions were $10 \mathrm{~min}$ at $95^{\circ} \mathrm{C}$ followed by 40 cycles of $95^{\circ} \mathrm{C}$ for $15 \mathrm{sec}$ and $60^{\circ} \mathrm{C}$ for $1 \mathrm{~min}$. The quantification data were analyzed with the SDS System Software (Applied Biosystems) and the relative expression levels were calculated according to the comparative $\mathrm{Ct}$ method, as $2^{-\Delta \Delta \mathrm{Ct}}$. Data are presented as the mean \pm standard error of the mean and statistically significant group differences were determined with Student's t-tests ( $\mathrm{p}$-value of $<0.05$ ).

Western blotting. Proteins were extracted from benign myoepithelial (PA) cells with RIPA buffer and were quantified by BCA Protein Assay (Thermo Scientific). Protein extracts were separated in a $15 \%$ SDS-polyacrylamide gel following 


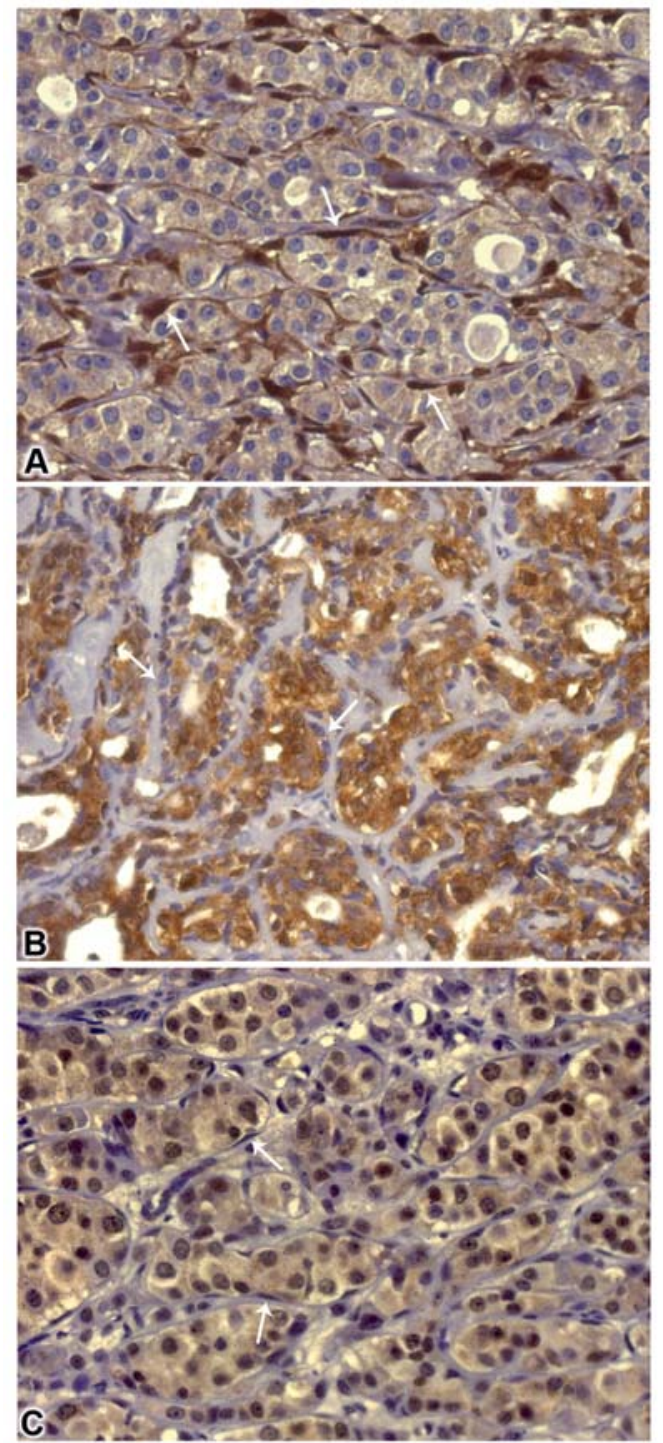

Figure 2. Immunohistochemical expression for FGF-2, FGFR-1 and FGFR-2 in areas of in situ carcinoma. The benign myoepithelial cells (arrows), surrounding the malignant epithelial cells (luminal), presented a strong expression of FGF-2 (A) and no staining for FGFR-1 (B) and FGFR-2 (C) on these cells. The malignant epithelial cells (luminal) immunostained FGF-2 (A) weaker than benign myoepithelial cells, and they also expressed FGFR-1 (B) and FGFR-2 (C) in the cytoplasm. In addition, they exhibited a strong expression of FGFR -1 and FGFR-2 in the nucleus. Original magnification (A-C), $\mathrm{x} 400$. transfer onto a nitrocellulose membrane (Hybond-ECL, GE Heathcare). FGF-2 proteins were detected with polyclonal FGF-2 antibody (1:800 dilution, Santa Cruz Biotechnology), peroxidase labeled secondary antibody (1:3000 dilution) and the ECL Plus Western Blotting Detection System (GE Healthcare).

\section{Results}

Immunohistochemistry. The immunohistochemical reactions are shown in Fig. 2. In all cases presenting in situ structures, the benign myoepithelial cells surrounding the malignant epithelial cells (luminal) presented a high expression of FGF-2 in the cytoplasm and in the nucleus (Fig. 2A). However, no staining was observed for FGFR-1 (Fig. 2B) and FGFR-2 (Fig. 2C) on these cells. The malignant epithelial (luminal) cells presented lower FGF-2 staining than benign myoepithelial cells (Fig. 2A). They also expressed FGFR-1 and FGFR-2 in the cytoplasm and also in the nucleus (Fig. 2B and $\mathrm{C}$ ).

Immunofluorescence. In order to better understand these results we conceived an in vitro study attempting to simulate in situ areas of CXPA, where the benign myoepithelial cells were conditioned by the malignant cells in culture medium. FGF-2 was immunoexpressed in all benign myoepithelial cell cultures, independently of conditioned medium (HN30) stimulation, and was detected as punctuate deposits throughout the cytoplasm (Fig. 3). However, we could not affirm that there were differences between benign myoepithelial cells cultured in conditioned medium when compared to the control benign myoepithelial cells.

$q P C R$ and Western blotting. In order to quantify the results obtained by immunofluorescence, we further assessed in vitro the potential influence of malignant cells on FGF-2 expression in benign myoepithelial (PA) cells. qPCR showed that FGF-2 mRNA was significantly up-regulated in PA cells following stimulation with HN30 (malignant) cells culture medium when compared to non-stimulated conditions (Fig. 4A). This up-regulation was confirmed by the levels of FGF-2 protein evaluated by Western blotting (Fig. 4B). Our protein analysis also demonstrated that LMW (18 kDa) as well as HMW
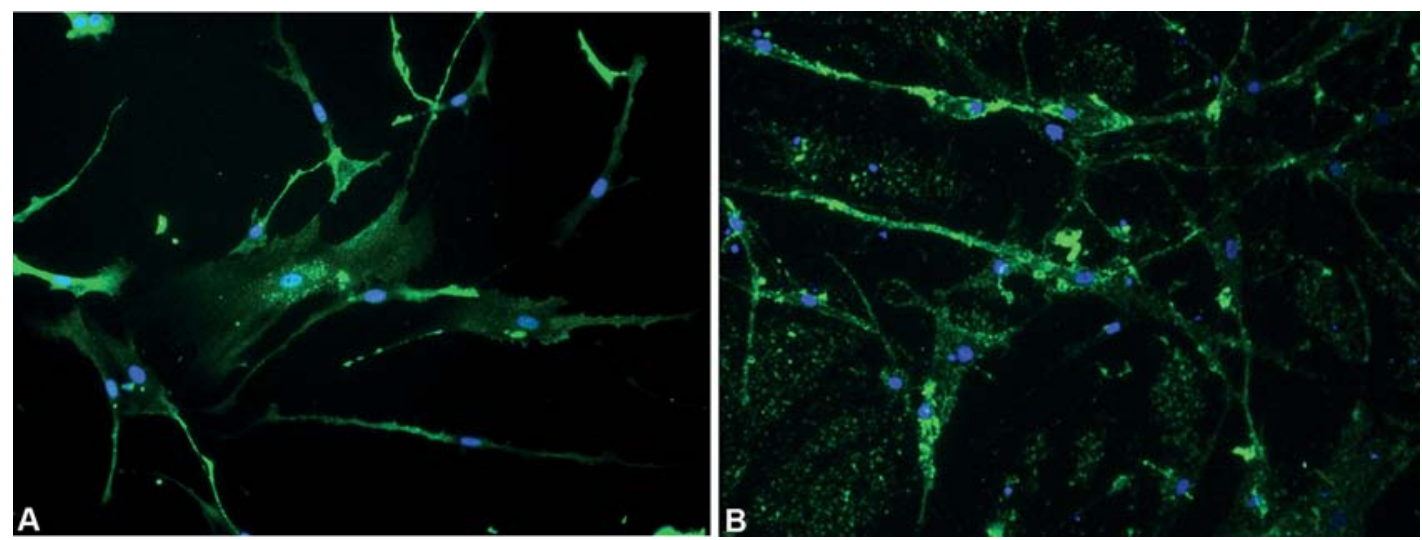

Figure 3. Immunostaining for FGF-2 in benign myoepithelial cells and benign myoepithelial cells cultured with HN30 medium. The FGF-2 immunolabeling appeared as punctuate deposits throughout the cytoplasm. Original magnification (A), x400; (B), x200. 
A

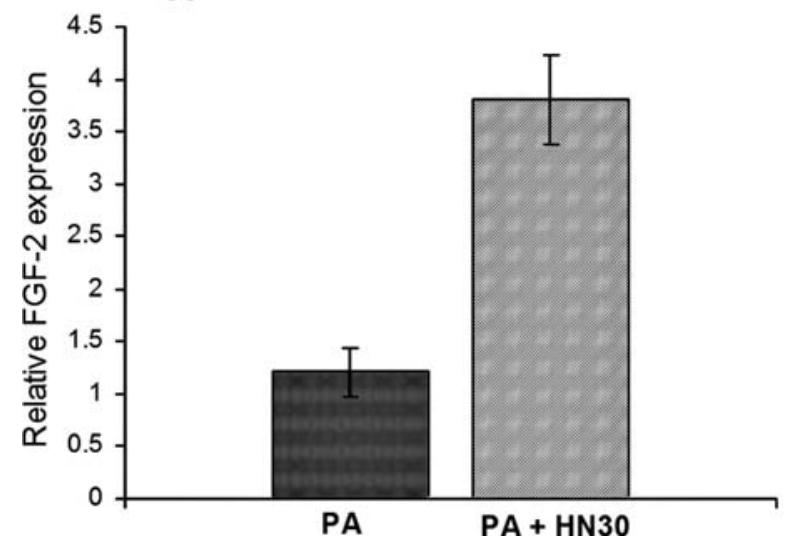

B

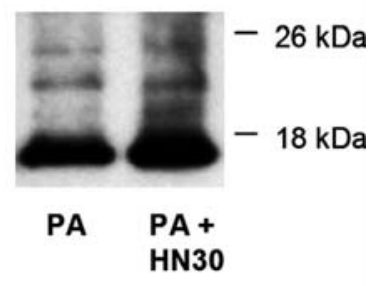

Figure 4. Relative FGF-2 expression. (A) Real-time PCR showing significant up-regulation of FGF-2 mRNA in PA cells after stimulation with HN30 culture medium (PA+HN30) compared to normal culture conditions (PA) ( $\mathrm{p}=0.0008)$. (B) Western blotting illustrating FGF-2 protein forms from PA cells, LMW $(18 \mathrm{kDa})$ and HMW (22, 22.5 and $24 \mathrm{kDa})$ and relative increase of LMW FGF-2 after stimulation with HN30 culture medium (PA+HN30) compared to normal culture conditions (PA). Results represent 3 independent experiments.

(22, 22.5 and $24 \mathrm{kDa})$ forms of FGF-2 were present in PA cells, independently of the stimulation (Fig. 4B).

\section{Discussion}

Our immunohistochemical results have shown the expression patterns of FGF-2 and its receptors in the benign myoepithelial and malignant epithelial cells comprising in situ structures of CXPA. We have observed that benign myoepithelial cells overexpress FGF-2, which could be found in the cytoplasm and in the nucleus. Among several growth factors studied, including TGF-ß, HGF, PDGF-A, EGF and IGF, FGF-2 was the only one detected in benign myoepithelial cells of CXPA in situ structures (unpublished data). In the epithelial cells, lower levels of this growth factor were observed. Regarding the FGF-2 receptors, FGFR-1 and FGFR-2, while not detected in benign myoepithelial cells, both were expressed in the epithelial cells (Fig. 2).

In order to better understand these results we conceived an in vitro model attempting to simulate the cellular interactions of in situ structures of CXPA. In this model, the benign myoepithelial cells were conditioned by the malignant cell culture medium. For this, we have employed cultures of PA cells from minor salivary gland, known to be rich in myoepithelial cells (20). In the present study, this was confirmed by the immunophenotype of PA cells, which were positive for the major myoepithelial cell markers (anti- $\alpha$ smooth muscle actin, anti-calponin and anti-vimentin) and mostly negative for luminal cell markers (CK-7 and AE1/AE3). In addition, growth factors that promote the outgrowth of epithelial cells were not added to the cell cultures.

Our immunofluorescence results, supported by the qPCR and Western blotting analyses, demonstrated that in fact the expression of FGF-2 in the benign myoepithelial (PA) cells was increased by stimulation by the conditioned medium obtained from malignant cells (HN30). Therefore, the benign myoepithelial cells under the influence of conditioned medium underwent phenotypic alteration represented by an increased FGF-2 content.
The immunohistochemistry showed that FGF-2 was expressed in both cytoplasm and nucleus of the myoepithelial (PA) cells. In agreement, we have detected LMW and HMW forms of FGF-2 in our immunoblotting assay, forms which are known to be differentially distributed in the cells, LMW in the cytoplasm and HMW in the nucleus (Fig. 4B). HMW FGF-2 forms are known to act through an intracrine mechanism, directly regulating gene expression $(13,14)$, which may be responsible for the final differentiation-related phenotype achieved by benign myoepithelial cells of in situ structures of CXPA, previously reported by our group (3).

Despite the detection of diverse FGF-2 forms, our results clearly demonstrated that the LMW was the predominant FGF-2 protein structure expressed in the benign myoepithelial cells, even augmented after stimulation with malignant cell culture medium (Fig. 4B). Considering that this FGF-2 form is primarily released from the cells to exert its biological activity through receptors, and that we found specific FGF-2 receptors in the malignant epithelial but not in the benign myoepithelial cells of CXPA, our results indicate a paracrine role for myoepithelial cell-derived FGF-2. This role was previously suggested to control survival and growth of epithelial cells in the normal human breast (21). Moreover, FGF-2 released from breast myoepithelial cells was reported to have no effect on the proliferation of their counterparts, dismissing an autocrine action (21). This was compatible with the lack of FGF-2 receptors in benign myoepithelial cells of CXPA observed in our immunohistochemical analysis. On the other hand, receptors for this growth factor were abundantly found in epithelial cells of CXPA, which could take advantage of the prominent availability of FGF-2 for proliferation and migration. In line with our findings, it was demonstrated that myoepithelial cells undergo dramatic changes in gene expression throughout the progression of normal breast tissue to invasive breast carcinomas, changes already evident at the in situ carcinoma stage, able to enhance the proliferation, migration and invasion of the tumor (22). Interestingly, genes encoding secreted and cell surface proteins accounted for the majority of the differentially expressed cells in myoepithelial cells composing breast tumor (22). Although not FGF-2- 
related, a role for myoepithelial cells in breast tumor progression has been previously suggested (22), supporting our findings.

Considering the architecture of the salivary gland tissue, it is reasonable to propose that the effects of myoepithelial cell-derived FGF-2 could extend beyond luminal epithelial cells of CXPA. This growth factor could reach corresponding receptors on the surface of stromal cells, such as fibroblasts, adipocytes and endothelial cells. Of particular importance is its pro-angiogenic effect over endothelial cells, demonstrated to modulate their proliferation, migration, protease production and expression of integrin and cadherin receptors $(17,23)$. In this manner, FGF-2 could participate in the vascularization switch of CXPA, which would become prone to the invasion of malignant epithelial cells from the in situ areas of this tumor. In mammary gland, the formation of a vascularized stroma was found to precede invasion of tumor cells from in situ areas $(24,25)$. It has been postulated that tumor cells do not invade into normal breast stroma but rather into a richly vascularized one which they have induced (26).

Despite the suppressive function of myoepithelial cells, our results and those from others suggest that, at certain point of the tumorigenic process, myoepithelial cells may receive divergent signals or a change in the balance among the signals may occur, which would enable them to promote opposite effects over both malignant luminal cells and the cells composing the tumor microenvironment, favoring invasion and metastasis. This highlights the importance of understanding the molecular basis of the transition from a preinvasive in situ stage to acquisition of the ability of invasion and metastasis. As a consequence, excessive release of this growth factor could lead to abnormal paracrine myoepithelial/epithelial cell interactions and also myoepithelial/stromal cell interactions, encouraging tumor growth, invasion and metastasis.

\section{Acknowledgements}

The authors wish to thank Audrey Jordão Basso, Jerusa Pinheiro and Pollyanna Tombini Montaldi for their excellent technical expertise and assistance. This study was supported by $\mathrm{CNPq}$ and FAPESP (grants 04/07960-0; 08/58721-7 and 08/58722-3).

\section{References}

1. Gnepp DR, Brandwein-Gensler MS, El-Naggar AK and Nagao T: Carcinoma ex pleomorphic adenoma. In: World Health Organization Classification of Tumours. Pathology and Genetics. Head and Neck Tumours. Barnes L, Eveson JW, Reichart P and Sidransky D (eds). IARC Press, Lyon, pp242-243, 2005.

2. Cheuk W and Chan JK: Advances in salivary gland pathology. Histopathology 51: 1-20, 2007.

3. Araújo VC, Altemani A, Furuse C, Martins MT and Araújo NS: Immunoprofile of reactive salivary myoepithelial cells in areas of in situ carcinoma ex-pleomorphic adenoma. Oral Oncol 42: 1011-1016, 2006.

4. Ke Y, Fernig DG, Wilkinson MC, et al: The expression of basic fibroblast growth factor and its receptor in cell lines from normal human mammary gland and a benign mammary lesion. J Cell Sci 106: 135-143, 1993.

5. Jones JL, Shaw JA, Pringle JH and Walker RA: Primary breast myoepithelial cells exert an invasion-suppressor effect on breast cancer cells via paracrine down-regulation of MMP expression in fibroblasts and tumour cells. J Pathol 201: 562-572, 2003.

6. Barsky SH and Karlin NJ: Myoepithelial cells: autocrine and paracrine suppressors of breast cancer progression. J Mammary Gland Biol Neoplasia 10: 249-260, 2005.
7. Polyak K and $\mathrm{Hu} \mathrm{M}$ : Do myoepithelial cells hold the key for breast tumor progression? J Mammary Gland Biol Neoplasia 10: 231-247, 2005.

8. Gudjonsson T, Adriance MC, Sternlicht MD, Petersen OW and Bissell MJ: Myoepithelial cells: their origin and function in breast morphogenesis and neoplasia. J Mammary Gland Biol Neoplasia 10: 261-272, 2005

9. Man YG and Sang QX: The significance of focal myoepithelial cell layer disruptions in human breast tumor invasion: a paradigm shift from the 'protease-centered' hypothesis. Exp Cell Res 301: 103-118, 2004.

10. Shao ZM, Nguyen M, Alpaugh ML, O'Connell JT and Barsky SH: The human myoepithelial cell exerts antiproliferative effects on breast carcinoma cells characterized by p21WAF1/CIP1 induction, G2/M arrest, and apoptosis. Exp Cell Res 241: 394-403, 1998.

11. Gudjonsson T, Rønnov-Jessen L, Villadsen R, Rank F, Bissell MJ and Petersen OW: Normal and tumor-derived myoepithelial cells differ in their ability to interact with luminal breast epithelial cells for polarity and basement membrane deposition. J Cell Sci 115: 39-50, 2002

12. Bikfalvi A, Javerzat S, Perollet $C$ and Savona C: Angiogenesis and cancer. Bull Cancer 84: 885-890, 1997.

13. Delrieu I: The molecular weight isoforms of basic fibroblast growth factor (FGF-2): an insight into an intracrine mechanism. FEBS Lett 468: 6-10, 2000.

14. Yu P-J, Ferrari G, Galloway AC, Mignatti P and Pintucci G: Basic fibroblast growth factor (FGF-2): the high molecular weight forms come of age. J Cell Biochem 100: 1100-1108, 2007.

15. Plotnikov AN, Hubbard SR, Schlessinger J and Mohammadi M: Crystal structures of two FGF-FGFR complexes reveal the determinants of ligand-receptor specificity. Cell 101: 413-424, 2000.

16. Harmer NJ, Chirgadze D, Hyun Kim K, Pellegrini L and Blundell TL: The structural biology of growth factor receptor activation. Biophys Chem 100: 545-553, 2003.

17. Presta M, Dell'Era P, Mitola S, Moroni E, Ronca R and Rusnati M: Fibroblast Growth factor/fibroblast growth factor receptor system in angiogenesis. Cytokine Growth Factor Rev 16: 159-178, 2005.

18. Grose R and Dickson C: Fibroblast growth factor signaling in tumorigenesis. Cytokine Growth Factor Rev 16: 179-186, 2005.

19. Altemani A, Martins MT, Freitas L, Soares F, Araújo NS and Araújo VC: Carcinoma ex pleomorphic adenoma (carcinoma ex pleomorphic adenoma): immunoprofile of the cells involved in carcinomatous progression. Histopathology 46: 635-641, 2005.

20. Barsky SH and Alpaugh ML: Myoepithelium: methods of culture and study. In: Culture of Human Tumor Cells. Pfragner R and Freshney RI (eds). John Wiley \& Sons, NJ, pp221-260, 2004.

21. Gomm JJ, Browne PJ, Coope RC, Bansal GS, Yiangou C, Johnston CL, Mason R and Coombes RC: A paracrine role for myoepithelial cell-derived FGF2 in the normal human breast. Exp Cell Res 234: 165-173, 1997.

22. Allinen M, Beroukhim R, Cai L, Brennan C, Lahti-Domenici J, Huang H, Porter D, Hu M, Chin L, Richardson A, Schnitt S, Sellers WR and Polyak K: Molecular characterization of the tumor microenvironment in breast cancer. Cancer Cell 6: 17-32, 2004.

23. Avraamides CJ, Garmy-Susini B and Varner JA: Integrins in angiogenesis and lymphangiogenesis. Nat Rev Cancer 8: 604-617, 2008.

24. Brown LV, Guidi AJ, Schnitt SJ, van de Water L, IruelaArispe ML, Yeo TK, Tognazzi K and Dvorak HF: Vascular stroma formation in carcinoma in situ, invasive carcinoma and metastatic carcinoma of the breast. Cancer Res 5: 1041-1056, 1999.

25. Vleugel MM, Bos R, van der Groep P, Greijer AE, Shvarts A, Stel HV, van der Wall E and van Diest PJ: Lack of lymphangiogenesis during breast carcinogenesis. J Clin Pathol 57: 746-751, 2004.

26. Pavlakis K, Messini I, Vrekoussis T, Yiannou P, Keramopoullos D, Louvrou N, Liakakos T and Stathopoulos EN: The assessment of angiogenesis and fibroblastic stromagenesis in hyperplastic and pre-invasive breast lesions. BMC Cancer 2: 8-88, 2008. 